\title{
Research on the Application of Space Syntax in Urban Planning
}

\author{
Xi Chen \\ Changchun Architecture \& Civil Engineering College, Changchun, China \\ Email: fashiontrack@163.com
}

How to cite this paper: Chen, X. (2017) Research on the Application of Space Syntax in Urban Planning. World Journal of Engineering and Technology, 5, 29-35. https://doi.org/10.4236/wjet.2017.53B004

Received: June 19, 2017

Accepted: August 8, 2017

Published: August 11, 2017

\begin{abstract}
This paper presents the objective analysis of the application of space syntax in a large scale city design field and possible problems, and then introduces how to use quantitative techniques to enhance the science and rationality of the design on large scale city.
\end{abstract}

\section{Keywords}

Space Syntax, Urban Planning, Quantitative

\section{Introduction}

The design force after several years of development has played an important role in all areas of our city construction. City design theory system has been expanded, gradually from the previous "effect" of the design to the present throughout the planning process technical support. Looking at the field of city design, with the speed of city development and constantly improvement, city image, style, characteristics, problems continue to highlight the vitality of city design, special and detached outside the statutory planning system [1]. The city began to tend to become a design involving many aspects, covering a variety of scale and comprehensive design. In the process of development, the scale of city design from the past to the present development of a few hectares of hundreds of square kilometers, the complexity, diversity and uncertainty becomes more and more strong. In this context, some techniques commonly used in the design of small scale city in the face of large scale become clumsy lapel see elbow, small scale qualitative judgment, common experience in city design reasoning, space simulation and other means, and have been unable to meet the needs of large scale city design, or cannot guarantee the rationality of the design of large scale city, scientific and convincing. Therefore, in the face of such a situation, how to 
adjust the design ideas and technical means to improve the scale of the urban design of the rationality and scientific becomes imminent.

\section{Space Syntax and Large Scale Urban Design}

City design is different from the small scale to implement spatial form as the main goal, pay more attention to the design of large scale city on a large scale within the scope of a comprehensive understanding of regional issues, identify features and grasp the characteristics, identification structure, based on the summary of the content, form, has guiding significance for the preparation of lower city design and city planning "list", and eventually the whole area of face image control at global level, the city design can really be targeted, not only to highlight the city's character, but also can improve the structure and function of the city [2].

Because the scope relates to a large scale city design is often large, if not grasp the key, to accurately determine the city, will spend a lot of energy, and in the process of compiling the program, if only to rely on the experience and knowledge of planning planners, is the lack of sufficient evidence to prove their point of view, there may be due to its deviation the judge led to the failure of the plan results.

In practical work, the project team has been exploring a kind of technical method which can help the planners to carry on the rational and objective analysis. Suzhou city in the preparation of the overall design and process of the core area of Beijing business district expansion design competition, the project team and the founder of the University of London professor Hillier Bill of space syntax, using space syntax model of full participation in the project preparation, have played a positive effect in the field of cognition, previous research and analysis, program verification stage. Before the Hillier professor of space syntax in project portfolio, research is still no system for China the actual case, most of the current domestic space syntax practice cases are domestic researchers to use based on their own understanding of the lack of space syntax of the core data, the conclusion may be biased place. As for the space syntax theory system itself, due to the lack of test case, can adapt to the China situation also has some uncertainty, through the research and practice of the two projects, the project team hope to establish a large scale based on the level of "Chinese style" space syntax system.

\section{The Application of Space Syntax in the Overall Urban Design of Changchun}

The history of the Changchun prosperous and gathering of talents, but the former Changchun fairyland "almost become a reality in an earthly paradise" boring "world factory", facing enormous difficulties and challenges of the land, water, ecological environment, industrial competitiveness and cultural characteristics [3]. With the extension of the expansion of the main features of the urban growth mode led to the rapid development of the city there have been many 
problems. Administrative division, natural boundary segmentation, major infrastructure segmentation and other factors, resulting in the original comprehensive Changchun was cut into " $4+1$ " Changchun. Each with their own needs, hope to establish a complete set of city functions, the spatial structure of closed, resulting in a large number of redundant construction and vicious competition among projects, complementarity, coordination between the districts of Changchun eroding characteristics of the feudal era continue to appear, the overall structure of the city suffered serious damage.

2016, the author of the design team assumed the task of the overall urban design of Changchun, the entire planning area for the city center of Changchun, with an area of about $380 \mathrm{~km} 2$. After the investigation and preliminary analysis of the scene, decided to adopt the basic strategy of problem oriented, based on comprehensive and systematic analysis of the current situation, to develop targeted solutions, to promote the city structure of the original split can effectively unify, form a cohesive force. In order to ensure the integration of analysis and research rational, the project team decided to draw a number of quantitative analysis tools, from the whole process of the project, the space syntax in the following two stages played a more important role.

\section{Stage of Research}

In the early stage of urban problem identification and judgment, the space syntax help design team understands the existing problems of Changchun's urban structure from the perspective of spatial ontology. Based on the present situation, the space syntax company established the axis model, and analyzed the model according to the previous empirical data. At the same time, the project group of local students, closely related to traffic and street space syntax format, land layout and other basic data were collected and finishing work, and through the real survey data on school space syntax model [4].

After the check, determine the basic core element of Changchun space syntax analysis is the integration between the two turning angle and axis model, rather than the actual distance between two points, in addition, also on the related data were modified, the integration of distribution through the space syntax model modified by reflection the basically can coincide with the real situation, the correlation between the two reached a higher level. That is to say, after verification and adjustment of the space syntax model can basically reflect the real situation of Changchun urban spatial structure, so as to ensure the follow-up analysis can be reasonable. On the basis of this model, the project groups were analyzed for the spatial integration of different scales in Changchun city center.

First, from the space perspective, Changchun Downtown on the whole has not yet formed in various regions closely linked to the overall structure of the city, the mutual isolation between the old city and the surrounding area four, and the level of integrity of the old city spatial structure is significantly higher than the surrounding area by any radius based analysis of Changchun center city in the 
comprehensive potential of the regional level through the traffic and arrival traffic, from the integration of the distribution situation, people can find space within the city limits of active center and the old city, a high degree of integration of the path out of the range of sharp attenuation, basically do not extend to play in other areas [5], resulting in the area between each city cannot achieve smooth close contact: at the same time, compared to the surrounding and high tech Zone Industrial Park, the city and the old city was out Have a clear, spatial network structure, and all levels of the distribution center is obvious: this conclusion is from the space ontology perspective to verify the project group for Changchun city " $4+1$ " city of the overall structure of the barony judgment.

Second, space syntax auxiliary city designers more accurately grasp the travel rules of local residents, without considering other factors, relying solely on the integration of spatial analysis based on ontology, we can find the integration degree and corresponding to a certain scale of Transportation traffic has a very high correlation. By comparing the vehicle and non vehicle observation data with different scale integration model, the author found that the correlation of spatial integration and traffic statistics data in the range of $10-20 \mathrm{~km}$ can reach about $72 \%$. It can be determined that the average radius of Changchun car is 10 $20 \mathrm{Km}$. In comparison with non motorized traffic observation data, can be found in the range of $5-10 \mathrm{~km}$ spatial integration and actual observation data correlation in about $64 \%$, which can determine the Changchun average bicycle travel radius is $5-10 \mathrm{~km}$, similarly, we also analyzed Changchun local walking radius is about $2 \mathrm{~km}$, especially in the old city and the city within the range of correlation reached above $77 \%$.

The main function of the space syntax in the program design phase is three parts: the identification of the potential space, the determination of the key nodes, the verification of the local and the whole scheme. That is the basis of integrated analysis of the spatial situation of space syntax model, spatial distribution of integration of different scales, high potential identification status and potential, by planning to obtain high potential areas, and then put forward the corresponding design strategy in different areas [6]. In addition, on the basis of present situation of the construction and land consolidation conditions, according to the planning design, selected key areas as the key areas in the future city fitting structure, and puts forward the solution, and then through the space syntax check scheme, to ensure that the final solution can have a positive impact on the city and the region.

First of all, from the perspective of space syntax, the purpose is to rationally utilize the space high potential of the integration sequence as much as possible to create a high degree of integration, space level rich, so that the city this organism can reasonably and effectively operate. In the process of Changchun overall city design, the current format, the use of space and space syntax comparison integration model, the author found that the existing Changchun status of several commercial gathering area can be reflected in the space syntax model, the inte- 
gration of strength and different business gathering area in the performance analysis under different radius the difference of their corresponding service radius is different. Among them, from the radius to the radius of the infinite $3 \mathrm{~km}$, Tong Jing Road, the northern end of the integration of commercial street continued to strengthen, where the radius of $3 \mathrm{~km}$ reached the highest, the author to determine the main service radius of the commercial street is about $3 \mathrm{~km}$. On the basis of the above analysis, based on the basic idea of function promotion, retention of rectification, the initial development of the Changchun future major city service center level system, a high degree of integration for large scale areas, the future of the region may become a municipal business service center, similarly, the integration of regional and small scale in scale may become the area level, community level, under this premise, the proposed adjustment of different areas of commercial activities, so as to make the space potential and its corresponding function.

\section{Site Visibility Analysis}

With the help of software space syntax, project visibility of the final solution is analyzed, the analysis is actually on the axis of the amplification integration analysis based on the scale, the original with a representative of the space axis amplification has become an actual area of open space, possibly carrying countless root axes of the space, integration analysis of plane according to the basic principle of axis graph analysis, and summarized to visibility of open space, the analysis is helpful to further verify the rationality of the open space system, at the same time to determine flow law in practical activities in the open space and design space syntax: from favorable experience, high safety high visibility, with all-weather popular attraction, has high value to the business, in addition, high visibility The area is suitable for the establishment of important landmark public facilities or the layout of the main activities [7].

The visibility of the final solution of the analysis found that in the region as a whole scale level, local sections with high visibility, so these sections can be set along the regional service industry, but also should take the regional public activities function, and visibility of the central public park is the highest in the base, and the whole area into a CBD regional public activity center's goal is the same; at the local scale level. Identify the area of public service and commercial pedestrian street in the northwest side of base area has a high visibility, and the public in the planning layout format is consistent, while the scale of visual strength grade and planning of open space system is basically the same; in addition, the original power plant set in the large open space, the Chaoyang Road North and South Corridor effectively Strengthen the CBD area and the old city residential areas of line of sight, which is also consistent with the design of the idea.

\section{Summary}

Based on the above two specific cases, the author believes that the rational and quantitative urban design ideas are based on the accurate, objective and com- 
prehensive understanding of the current situation. The establishment of a set of possible achievement evaluation system through the status of cognition, planning and design must be analyzed based on the evaluation system, so as to verify the correspondence between planning objectives and results. If deviations arise, adjustments must be made to ensure that the final solution is reasonable. In addition, the author also emphasizes that when introducing advanced foreign technology, we should make an objective analysis of the specific circumstances and specific cases in our country, rather than simply apply, only the method through the practice of checking, in order to truly achieve the objective and rational.

Specific to the space syntax in the use of large scale city design, the author thinks that the method used shall comply with the following procedures: 1 . Based on the present situation of the establishment of an accurate grasp of kernel space syntax model, through the detailed investigation and research to ensure the authenticity and validity of this model; in the situation of the model, analysis of the current situation of the space area or city level problems as well as potential opportunities for development, determine the focus area, the next step for the specific design and provide the basis for the formulation of planning strategies; the model is verified by the design scheme of the overall planning and focus area, the design scheme and space syntax model check interactive form, and gradually improves the rationality of the program; after the final project is determined, a complete spatial syntactic report should be formed to describe the function of the method in the whole process of urban design, so as to provide reference and data support for the follow-up.

In general, the space syntax in a large scale city design does not play a leading role. It is a kind of spatial planning and spatial decision aid. The variable is not representative of all the people of the city space. Analysis of the use of space syntax and intuitive model as a quantitative interpretation status of the city spatial structure, identify potential space and activities of the public law potential tool have a certain value, but the overall idea of design or a higher level of decision objectives must be served. In order to further explain the significance of spatial syntax for large scale urban design, it is necessary to objectively evaluate the contribution and the shortcomings of this method.

The use of space syntax, provides a platform for the combination of rational analysis in the design of city space and traditional spatial perception received, overcomes the problems in the analysis phase space mature framework and detailed data are difficult to specific planning and implementation, to a certain extent make up for the complex city society interior space analysis method.

Space syntax provides a way of thinking purely from the spatial ontology, which is consistent with the nature of urban design. With the development of the design of the city, more and more functions are attached to the space, and the nature of the space has been gradually ignored. However, the large scale urban design is too difficult to start because of its large design range. There is no concrete image (which is the best area of urban design), and it is difficult to 
reach a consensus on the basis of language representation. Space syntax provides a visual spatial model for designers and researchers. It not only brings people's attention back to the discussion of the spatial ontology, but also provides a new way for us to communicate with each other.

\section{References}

[1] Chiaradia, A.J. and Xiao, Y. (2014) The Discussions on How to Implement Space Syntax Method for Urban Planning. Ciência Rural, 67, 109-114.

[2] Yang, T.H. and Chen, Y. (2013) Preliminary Discussion on Methods of Sculpture Design in Urban Landscape Environment. Applied Mechanics \& Materials, 409410, 738-741. https://doi.org/10.4028/www.scientific.net/AMM.409-410.738

[3] Jiao, L. (2015) Urban Land Density Function: A New Method to Characterize Urban Expansion. Landscape \& Urban Planning, 139, 26-39. https://doi.org/10.1016/j.landurbplan.2015.02.017

[4] Jiang, B., Larsen, L., Deal, B., et al. (2015) A Dose-Response Curve Describing the Relationship between Tree Cover Density and Landscape Preference. Landscape \& Urban Planning, 139, 16-25. https://doi.org/10.1016/j.landurbplan.2015.02.018

[5] Jiang, B., Chang, C.Y. and Sullivan, W.C. (2014) A Dose of Nature: Tree Cover, Stress Reduction, and Gender Differences. Landscape \& Urban Planning, 132, 26 36. https://doi.org/10.1016/j.landurbplan.2014.08.005

[6] Bentz, B.J., Boone, C. and Raffa, K.F. (2015) Tree Response and Mountain Pine Beetle Attack Preference, Reproduction and Emergence Timing in Mixed Whitebark and Lodgepole Pine Stands. Agricultural \& Forest Entomology, 17, 421-432. https://doi.org/10.1111/afe.12124

[7] Chen, Y. (2008) A Wave-Spectrum Analysis of Urban Population Density: Entropy, Fractal, and Spatial Localization. Discrete Dynamics in Nature \& Society, 2008, $47-$ 58. https://doi.org/10.1155/2008/728420

\section{Submit or recommend next manuscript to SCIRP and we will provide best service for you:}

Accepting pre-submission inquiries through Email, Facebook, LinkedIn, Twitter, etc. A wide selection of journals (inclusive of 9 subjects, more than 200 journals) Providing 24-hour high-quality service User-friendly online submission system Fair and swift peer-review system Efficient typesetting and proofreading procedure Display of the result of downloads and visits, as well as the number of cited articles Maximum dissemination of your research work

Submit your manuscript at: http://papersubmission.scirp.org/ Or contactwjet@scirp.org 